OPEN ACCESS

Edited by:

Marcello Rosa,

Monash University, Australia

Reviewed by:

Leah Krubitzer,

University of California, Davis,

United States

Rodrigo Suárez,

The University of Queensland,

Australia

*Correspondence:

Antonio Pereira

apereira@ufpa.br

tThese authors have contributed equally to this work

Received: 03 November 2018 Accepted: 27 December 2018

Published: 14 January 2019

Citation:

Santiago LF, Freire MAM

Picanço-Diniz CW, Franca JG and

Pereira A (2019) The Organization and Connections of Second

Somatosensory Cortex in the Agouti.

Front. Neuroanat. 12:118.

doi: 10.3389/fnana.2018.00118

\section{The Organization and Connections of Second Somatosensory Cortex in the Agouti}

\author{
Lucidia F. Santiago ${ }^{1 \dagger}$, Marco Aurelio M. Freire ${ }^{2 \dagger}$, Cristovam W. Picanço-Diniz ${ }^{1}$, \\ João G. Franca ${ }^{3}$ and Antonio Pereira ${ }^{4 *}$
}

\begin{abstract}
${ }^{1}$ Laboratory of Investigations in Neurodegeneration and Infection, Institute of Biological Sciences, Federal University of Pará, Belém, Brazil, ${ }^{2}$ Laboratory of Experimental Neuroprotection and Neuroregeneration, Institute of Biological Sciences, Federal University of Pará, Belém, Brazil, ${ }^{3}$ Institute of Biophysics Carlos Chagas Filho, Federal University of Rio de Janeiro,

Rio de Janeiro, Brazil, ${ }^{4}$ Institute of Technology, Federal University of Pará, Belém, Brazil
\end{abstract}

In order to understand how the mammalian sensory cortex has been structured during evolution, it is necessary to compare data from different species across distinct mammalian lineages. Here, we investigated the organization of the secondary somatosensory area (S2) in the agouti (Dasyprocta aguti), a medium-sized Amazonian rodent, using microelectrode mapping techniques and neurotracer injections. The topographic map obtained from multiunit electrophysiological recordings were correlated with both cytochrome oxidase (CO) histochemistry and with patterns of corticocortical connections in tangential sections. The electrophysiological mapping of the lateral strip of parietal cortex adjacent to the primary somatosensory area (S1) revealed that S2 displays a mirror-reversed topographical representation of S1, but with a smaller cortical magnification factor. The caudal border of S2 is surrounded by sensory fields which also respond to auditory stimulation. BDA injections into the forelimb representation of S2 revealed a dense homotopic ipsilateral projection to S1, supplemented by a less dense projection to the caudolateral cortex located near the rhinal sulcus (parietal rhinal area) and to a frontal region probably associated with the motor cortex. Our findings were similar to those described in other mammalian species, reinforcing the existence of a common plan of organization for S2 in the mammalian parietal cortex.

Keywords: S2, somatotopic map, cortical connections, agouti, rodent

\section{INTRODUCTION}

The organization of the mammalian somatosensory cortex has been the subject of scrutiny since the pioneer studies of Gerard et al. (1933) and Marshall et al. (1937). In these works, the authors identified an area responsive to tactile stimuli located in the parietal lobe of both monkeys and cats (Gerard et al., 1933; Marshall et al., 1937). The experimental evidence for a secondary somatosensory area (S2) was first provided by Adrian (1940), who described an additional cortical representation of the cat's feet next to the previously defined "first" somatosensory area (Adrian, 1940). Later on, with further development of microelectrode recording techniques and the rise of modern anatomical tract-tracing methods, the definition of both the organization and the limits of cortical areas became more reliable, enabling the identification of other somatosensory areas that 
had not previously been described, such as the parietal ventral (PV) and parietal rhinal (PR) areas (Krubitzer et al., 1986; Fabri and Burton, 1991).

The existence of multiple somatosensory fields in the cortex is a feature shared by all mammals (Kaas, 2011). Since monotremes, such as the platypus and the echidna, whose lineage emerged very early from the mammalian evolutionary branch (Divac, 1995), possess three separate somatosensory fields, S1, S2/PV, and a rostral field (R) (Krubitzer, 1998), it is argued that the multiplicity of tactile representations is a characteristic of the mammalian therapsid ancestors as well (Krubitzer and Kahn, 2003). The number of sensory fields seems to be closely associated with increments in both the complexity and scope of mammalian behavior (Kaas, 1989). According to this view, each sensory area is responsible for the extraction of different information from the environment while providing a connection with motor circuits controlling purposeful movements (Metzner and Juranek, 1997). For instance, in humans, whose behavior displays a strong reliance on vision, more than $20 \%$ of the entire cortex is devoted to visual processing distributed in about forty visual areas (Kaas, 1989; Wandell et al., 2007). However, the same is not true for the somatosensory modality, with most studies acknowledging the existence of only S1 and S2 and their intrinsic cytoarchitectonic subdivisions in humans (Eickhoff et al., 2006a,b).

Throughout evolution, the emergence of sensory fields in the cortex is shaped by the interplay between functional (Patel et al., 2014) and developmental constraints (Huntenburg et al., 2017). To get a clear picture of how these constraints interact, it is necessary to perform studies investigating the correlation of brain features with ecological and behavioral adaptive variables in species with different lifestyles, since a comparative approach is essential for the understanding of brain organization and function (Moss, 2018). Rodents comprise the largest and more diversified order among mammals, being represented by more than two thousand species grouped into 34 families (Wilson and Reeder, 2005) displaying the broadest ecological diversity and are a valuable target for such studies. Rodents are particularly diversified in South America, which remained isolated from other continents during the Cenozoic era and is now home to some of the biggest rodents on Earth, such as the genera Dasyprocta, Cuniculus, and Hydrochoerus (Nowak and Walker, 1999). South American rodents occupy a variety of habitats, ranging from the fossorial tuco-tuco (Ctenomys), the arboreal spiny rats (Echimyidae), the terrestrial agouti (Dasyprocta), and the semi-aquatic capybara (Hydrochoerus).

Despite the great variety of rodent species, however, our understanding of the organization and function of the rodent cortex is based mostly on results from two murine species: the house mouse (Mus musculus) and the laboratory rat (Rattus norvegicus) (Manger et al., 2008). This lack of diversity of experimental models hinders the goal of understanding the role of evolutionary constraints on cortical areal organization (Krubitzer, 1995; Catania and Kaas, 1997, 2001; Catania et al., 2000a; Catania and Remple, 2002; Patzke et al., 2014; Dooley et al., 2015; Jacobs et al., 2015). Along the years, our group has provided information on the organization of the central nervous system of a medium-sized (2.5-4.0 kg) South American rodent, the agouti (Dasyprocta aguti) (Figure 1A), including the visual (Picanço-Diniz et al., 1989; Elston et al., 2006; Freire et al., 2010; Rocha et al., 2012) and somatosensory cortices (Rocha et al., 2007; Santiago et al., 2010), as well as the spinal cord (Freire et al., 2008). The agouti possesses a relatively large brain compared to other rodents (Santiago et al., 2007) (see Figure 1B) and departs from many ways from common murine laboratory models in terms of body size, habitat, and behavior. Agoutis' behavior is characterized by being primarily diurnal and by its frugivorous nature, including the consumption of seeds and fruit pulp the animals had previously buried in caches or found on the forest floor (Henry, 1999). Interestingly, large portions of neural tissue both in the somatosensory thalamus (Campos et al., 1972) and S1 (Dias et al., 2014) receive projections from the forepaws and oral structures (lips, incisors) which are extensively used in eating behavior.

There are relatively few studies in rodents evaluating intracortical connections originating from S2 (Carvell and Simons, 1987; Koralek et al., 1990; Alloway et al., 2000). In the present investigation we try to fill this gap by providing information about the organization and hodological pattern of the agouti's S2 using a combination of multiunit electrophysiological recordings, tract-tracing with biotinylated dextran amine (BDA), and cytochrome oxidase (CO) histochemistry.

\section{MATERIALS AND METHODS}

\section{Animals and Ethics Statement}

We used six male adult agoutis (D. aguti) (2600 $\pm 175 \mathrm{~g})$, specimens donated by the Emilio Goeldi Zoo-Botanic Museum, under license from the Brazilian Institute of the Environment and Renewable Natural Resources (IBAMA) (ID 207419-0030/2003). All experimental procedures were approved by our institution's animal care and use committee (CEPAE-UFPA BIO001-10) and all efforts were made to avoid animal distress and to reduce the number of specimens used.

\section{Electrophysiological Recordings and Neurotracer Injection}

Animals were initially anesthetized with a mixture of ketamine hydrochloride $(46 \mathrm{mg} / \mathrm{kg}$ ) and xylazine hydrochloride (4 mg/kg) (i.m.). Throughout the course of the experiment, supplementary doses of the anesthetic mixture were administrated with a minimum interval of $1 \mathrm{~h}$ or whenever necessary. The anesthesia state was evaluated by monitoring the animal's respiration rate, cardiac rhythm, and both eye-blink and foot-pinch reflexes. After the animals were deeply anesthetized, they were placed in a stereotaxic head holder (Narishige Scientific Instruments, Tokyo, Japan) and a wide craniotomy was performed to expose the underlying somatosensory cortex of the left hemisphere. The dura mater was reflected, and the exposed cortical surface was protected with agar.

Recordings were made with low-impedance tungsten microelectrodes (0.8-1.2 M $\Omega$; FHC Inc., Bowdoinham, ME, United States). Electrode penetrations were made perpendicular 
to the cortical surface and each recording site was marked on an enlarged photograph of the exposed cortex. Blood vessels were used as landmarks to locate the position of electrode penetrations along the cortical surface. The neuronal signals were amplified, filtered, and sent to both an oscilloscope (1476A, BK Precision Inc., Yorba Linda, CA, United States) and a loudspeaker for the monitoring of multiunit receptive field (RF) responses. Somatosensory stimulation on the contralateral body surface consisted of light touches or pressure on the skin, deflection of hairs with a paintbrush, and gentle joint movements. We performed multiple sensory stimulations per recording site. Receptive fields were marked in drawings of the contralateral surface of the animal. In electrode penetrations aimed at regions posterior and lateral to S2, visual and auditory responses were also tested using light flashes and metallic clicks or taps, respectively.

Following the electrophysiological recordings, $0.4 \mu \mathrm{l}$ of lysinefixable biotinylated dextran amine (BDA, molecular weight 10,000; Molecular Probes Inc., Eugene, OR, United States) was injected by pressure into the electrophysiologically defined representation of the forelimb using a micropipette attached to a $1 \mu \mathrm{l}$ Hamilton microsyringe (Hamilton Company, Reno, NV, United States), which was introduced about $600 \mu \mathrm{m}$ deep into the cortical mantle. After the injection of the neurotracer, the pipette was left stationary inside the cortex for $5 \mathrm{~min}$ before being slowly withdrawn. The animals were then recovered from anesthesia and after a survival time of 15-30 days they were submitted to a new recording session in which four to six electrolytic lesions were made to allow reconstruction of electrode penetrations.

\section{Perfusion and Tissue Processing}

After the final electrophysiological recording, the animals were deeply anesthetized with urethane $(1.6 \mathrm{~g} / \mathrm{kg})$ and perfused transcardially with $0.9 \%$ saline followed by $4 \%$ paraformaldehyde in $0.1 \mathrm{M}$ phosphate buffer (PB) ( $\mathrm{pH}$ 7.4). The cortical hemispheres were separated from other brain structures, flattened between two glass slides, and left immersed in 0.1 M PB overnight. Both hemispheres were cut into $100 \mu \mathrm{m}$ thick sections with a Vibratome (Pelco International, Series 1000, Ted Pella Inc., Redding CA, United States). To reveal the BDA labeling, sections were first incubated overnight in a solution of the avidin-biotin complex (Vectastain ABC kit, Vector Laboratories, Burlingame, CA, United States; 1:200) and subsequently processed following the DAB/nickel method (Shu et al., 1988). Alternate sections were incubated in a $\mathrm{CO}$ solution containing $0.05 \%$ diaminobenzidine (DAB), $0.03 \%$ cytochrome $\mathrm{c}$ and $0.02 \%$ catalase in $0.1 \mathrm{M} \mathrm{PB}$ (Wong-Riley, 1979). Finally, sections were mounted in gelatincoated glass slides, left to air-dry overnight, dehydrated, cleared in xylene, and coverslipped with Entellan (Merck, Darmstadt, Germany).

\section{Tissue Reconstruction}

Camera Lucida drawings of the histological sections were made at low magnification with a Zeiss Stemi SV 11 optical microscope. The drawings included the following elements: section's outline, presence of $\mathrm{BDA}$ and/or $\mathrm{CO}$ labeling, electrolytic lesions, and major anatomical features

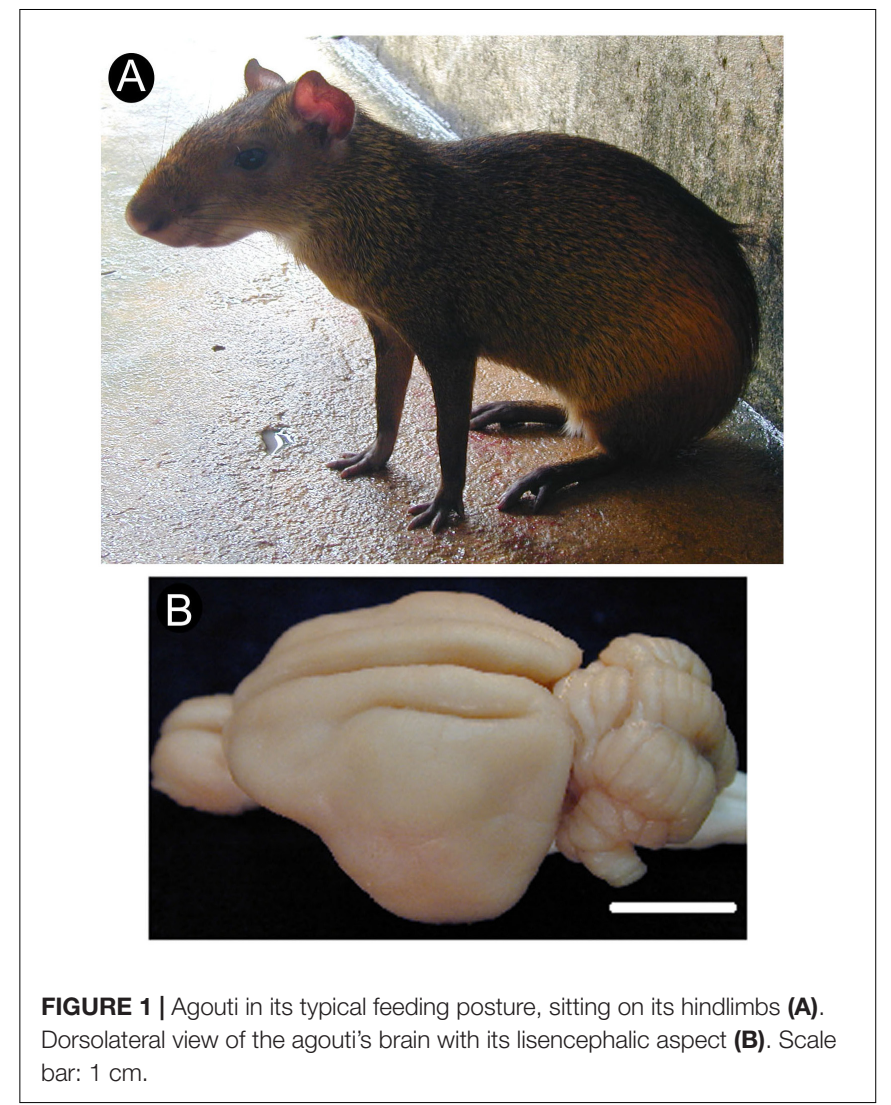

(e.g., sulci). The drawings of all sections from a given hemisphere were superimposed digitally with the Canvas software (ACD Systems Inc., Fort Lauderdale, FL, United States) using electrolytic lesions and blood vessels as landmarks. This procedure resulted in a combined 2-D reconstruction that incorporated both the somatotopic map obtained with the electrophysiological recordings and the information relative to both BDA and CO labeling. Photomicrographs were obtained with a Nikon AFX-DX Optiphot microscope (Tokyo, Japan). The contrast and/or brightness of pictures were adjusted with the Photoshop CS6 software (Adobe Systems Inc., San José, CA, United States). The areal extension of the representation of body parts in S2 was measured with the Image J software ${ }^{1}$, based in the electrophysiological maps (mean values from five electrophysiological maps), and expressed in percentiles, with the whole S2 representation corresponding to $100 \%$. Numerical values are expressed as mean \pm standard error of the mean (SEM). Statistical analysis was made using GraphPad Prism 5.0 (GraphPad Software Inc., La Jolla, CA, United States).

\section{RESULTS}

\section{Somatotopic Organization of S2}

We made a total of one hundred and forty-seven (147) microelectrode penetrations. The electrophysiological recordings

\footnotetext{
${ }^{1}$ https://imagej.nih.gov/ij/
} 

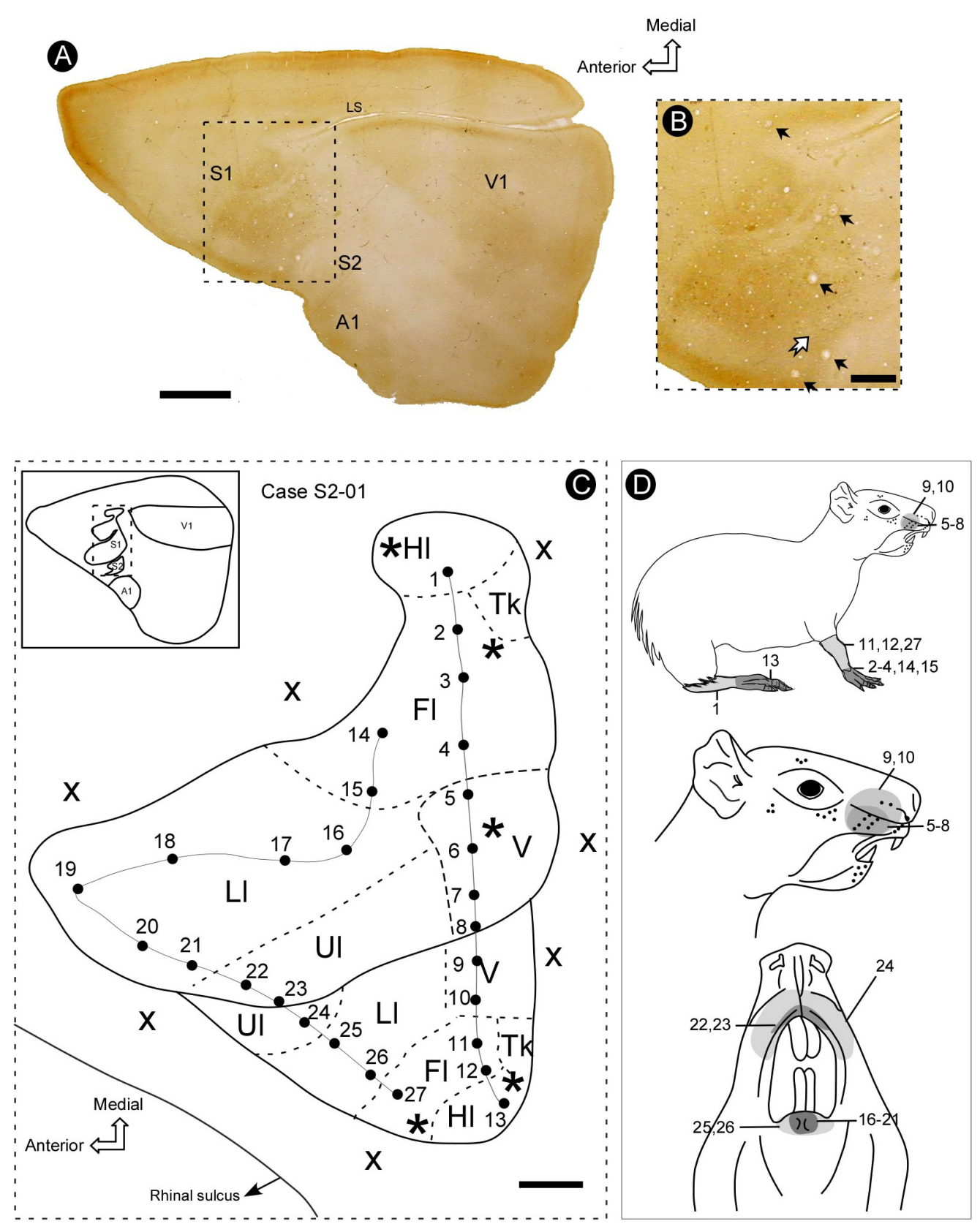

FIGURE 2 | Topographic organization of primary (S1) and secondary (S2) somatosensory areas of the agouti. (A) Section of the flattened cortex, processed for cytochrome oxidase (CO) histochemistry, revealing the location of primary somatosensory (S1), auditory (A1), and visual (V1) areas, as well as the secondary somatosensory cortex (S2). (B) Micrograph amplification showing S1 and S2 (medial portion) (dotted rectangle in A). Electrolytic lesions are indicated by black arrows. The limit between S1 and S2 is defined as a narrow strip of less reactive tissue (white arrow). (C) Topographic map of S1 and S2 reconstructed from recording sites. The limits of distinct body representations are delimited by dashed lines. Continuous lines indicate the reversal of receptive field sequences across S1 and S2 (penetrations 1-13 and 14-27). (D) Drawing of the agouti's body indicating the location of receptive fields illustrated in panel C. Grayscale codes indicate the difference in the size of receptive fields in both areas. Scale bars: A: 5 mm; B,C: 2 mm. Hl, hindlimb; Fl, forelimb; V, vibrissae; LI, lower lip; UI, upper lip; Tk, trunk; asterisk, electrolytic lesion; X, no response; LS, lateral sulcus.

revealed a complete representation of the contralateral body surface in S2, located just caudal and lateral to S1 (Figure 2). In all individual cases, the topographical representation of the contralateral body surface in S2 appeared as a mirror-reversed image of S1. Located in a lateral strip of the parietal cortex,
S2 is arranged with a rostral to caudal orientation with the representation of both limbs directed toward the lateral border of the cortex (see Figure 3).

The border between S1 and S2 was located along the representation of the head in both fields. The criteria employed 


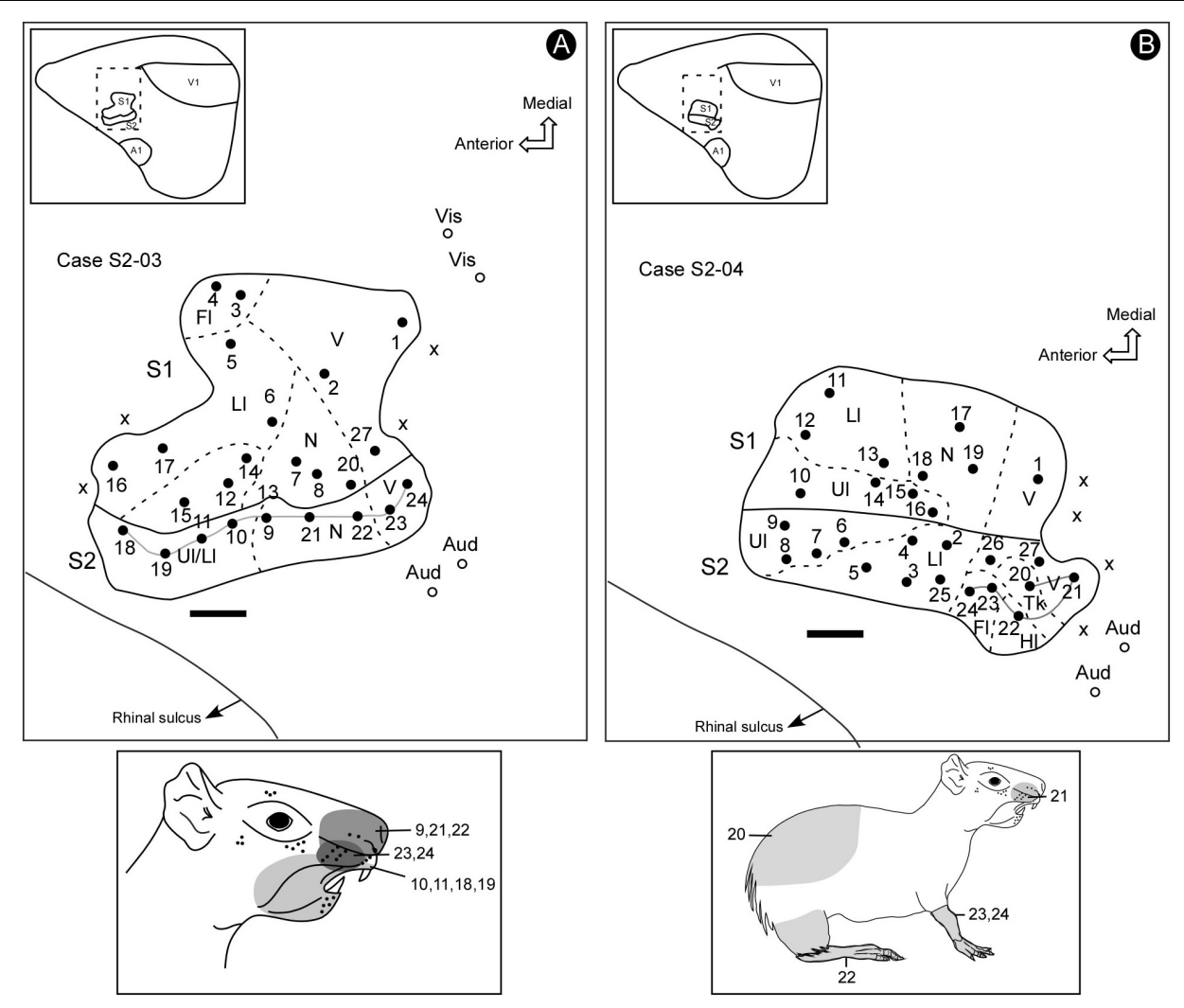

FIGURE 3 | Electrophysiological maps showing the organization of S2 and its relative location in the parietal cortex (inserts). S2 lies in a more lateral and posterior location in the parietal cortex, adjacent to the S1's face representation, containing a complete representation of the contralateral sensory periphery, which is smaller and has a mirror-symmetrical orientation compared to S1 (A,B). Receptive fields for associated electrode penetrations in cases S2-03 and S2-04 (continuous lines in maps in A,B). The shaded areas in the schematic drawings indicate the receptive fields for corresponding electrode penetrations in the electrophysiological maps. Scale bars: $1 \mathrm{~mm}$. FI, forelimb; HI, hindlimb; LI, lower lip; N, nose; Tk, trunk; Ul, upper lip; V, vibrissae; X, no response.

to estimate the areal limits included (i) the duplication of the representation of specific contralateral body parts and (ii) the reversion in the progression of receptive fields (RFs) along a continuous row of recording penetrations (Figure 2). In case S2-01, for instance, there is a topographic progression from the forelimb to lower and upper lip representations and back to lower lip and forelimb representations in a more lateral and caudal region, which corresponds to S2 (Figure 2). A clear reversion of the progression of RFs is noticed in electrode penetrations 20-26 (Figure 2C). Another RF sequence reversion can be seen in a sequence of penetrations along hindlimb and forelimb representations in S1 and then back to the hindlimb representation in S2 (Figure 2C).

The topography of the face representation in S2 has an anteroposterior disposition similar to S1, although with a mirror-reversed orientation and being smaller in size. In case S2-03 (Figure 3A), it is possible to notice that the more anterior and lateral recording sites have RFs with representations of both the upper and lower lips. In addition, the more posterior sites respond to both nose and vibrissae stimulation. The representation of the forelimb was situated lateral to the representation of the face and anterior to both the trunk and hindlimb representations (Figure 3B, case S2-04).
The representation of the trunk was located close to the representation of the face at the caudal border of S2. The representation of the hindlimb was located at more caudal and lateral segments of S2 (Figure 3B).

Some electrode penetrations, like those in cases S2-03 and S2-04 (Figures 3, 4), were exclusively responsive to auditory stimulation. These recording sites neighbored the region associated with the trunk and hindlimb representation in S2 (Figure 3B), where bimodal responses were also sometimes obtained (somatosensory plus auditory) (Figure 4). The presence of auditory responses in some electrode recordings was probably associated with the transition zone between S2 and the primary auditory cortex.

Both the anterior and the posterior boundaries of S2 were defined by the absence of somatosensory responses, whilst the lateral limit was defined by the presence of auditory activity at sites located close to the rhinal sulcus (Figure 4).

\section{Size of Individual Cortical Representations}

Based on measurements of the somatotopic map obtained with the microelectrode recordings, we were able to estimate the surface area occupied by the representation of specific 


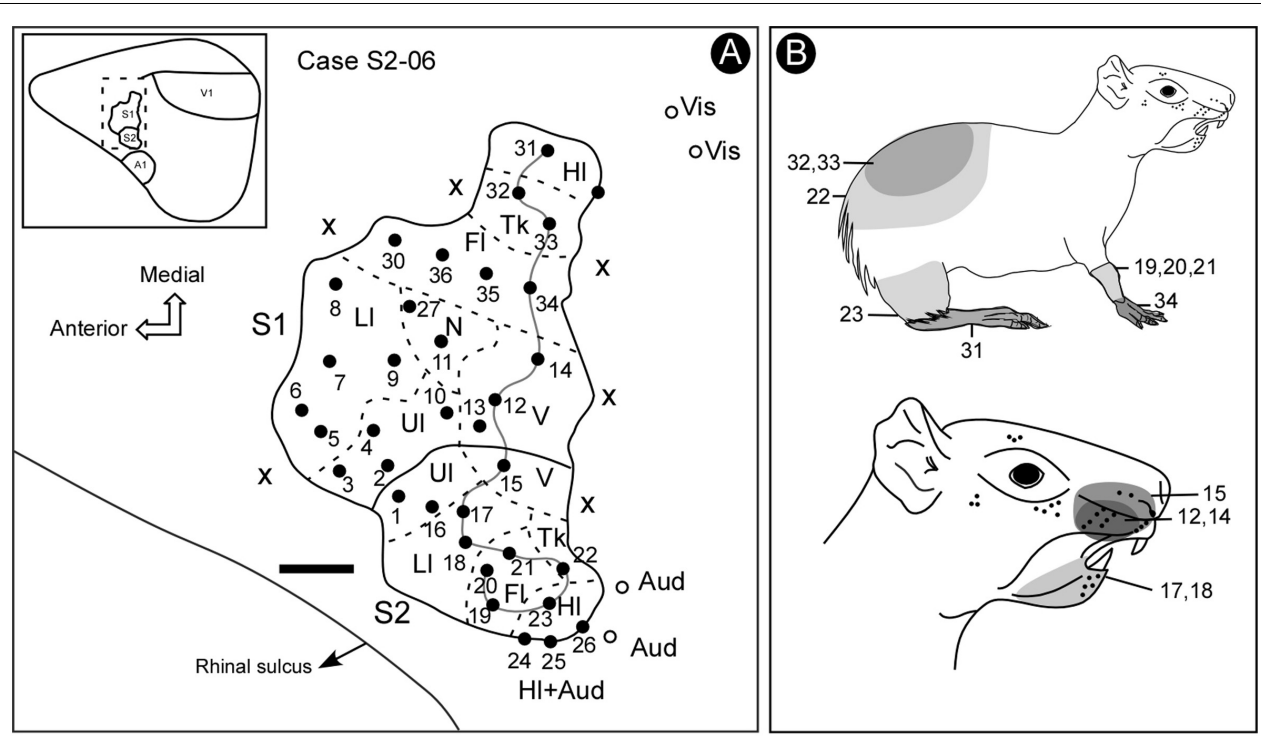

FIGURE 4 | Electrophysiological map (case S2-06) showing the location and organization of S2. Some bimodal responses were identified in a lateral region of S2, across the border with the auditory cortex. In more medial regions, beyond S1, it was possible to identify some visual responses. Notice the reversion in the progression of receptive field locations from S1 to S2 (continuous line) (A). The shaded areas in the schematic drawing indicate the receptive fields associated with corresponding electrode penetrations in the electrophysiological map, indicated by a continuous line (B). Scale bar: $1 \mathrm{~mm}$. Fl, forelimb; HI, hindlimb; LI, lower lip; N, nose; Tk, trunk; Ul, upper lip; V, vibrissae; X, no response.

B
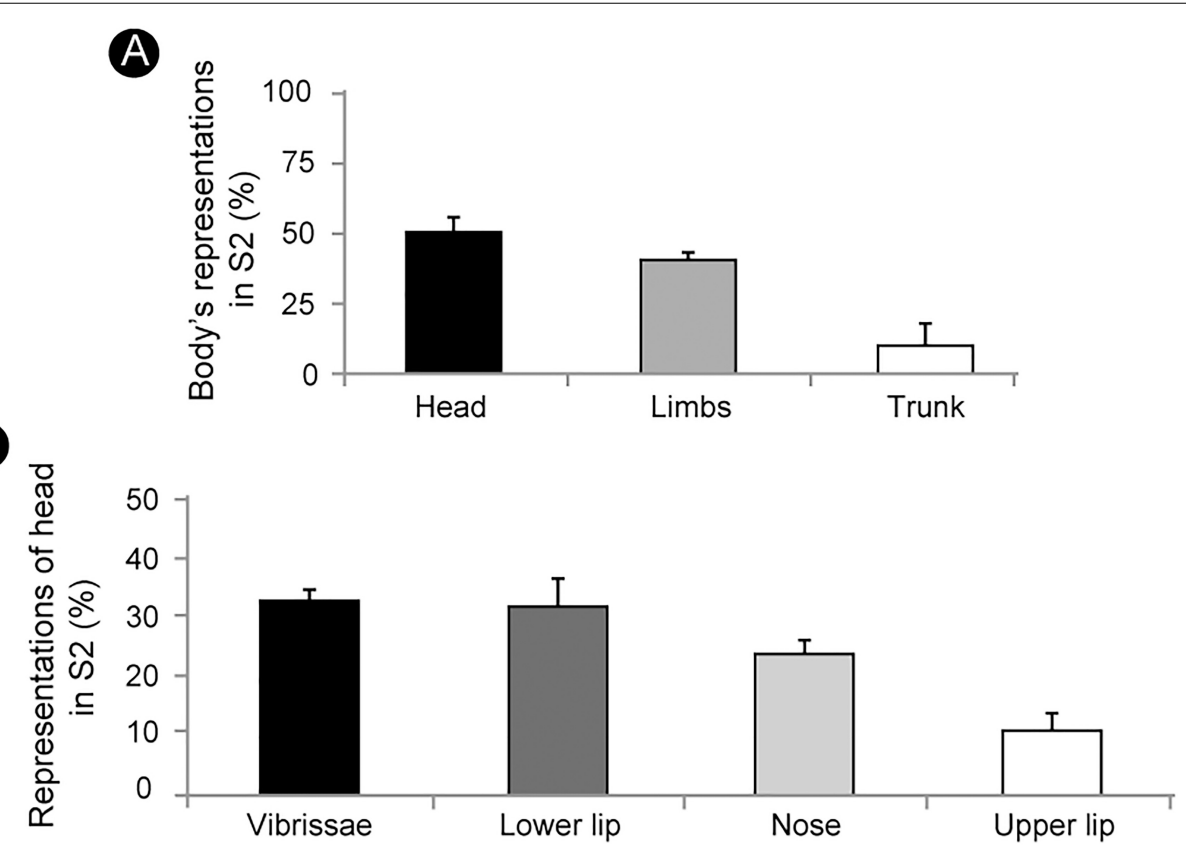

FIGURE 5 | The cortical area occupied by the representation of different body parts in S2. (A) About half of S2 is devoted to the representation of the head, followed by the representation of limbs (forelimb: 23\%; hindlimb: 17\%) and trunk (10\%). (B) Vibrissae (33\%) and lower lip (32\%) represent two thirds of the head's representation, followed by the nose (24\%) and upper lip (11\%) (mean \pm SEM).

body parts in S2. Thus, half of S2 is devoted to the representation of the face, followed by the representations of the forelimb (23\%), hindlimb (17\%) and trunk (10\%) (Figure 5A) (mean values from five electrophysiological maps).
Within the representation of the head the larger portion is devoted to the vibrissae (33\%) and the lower lip (32\%), while the nose and the upper lip occupy $24 \%$ and $11 \%$ of the area, respectively (Figure 5B) (mean values from five electrophysiological maps). 

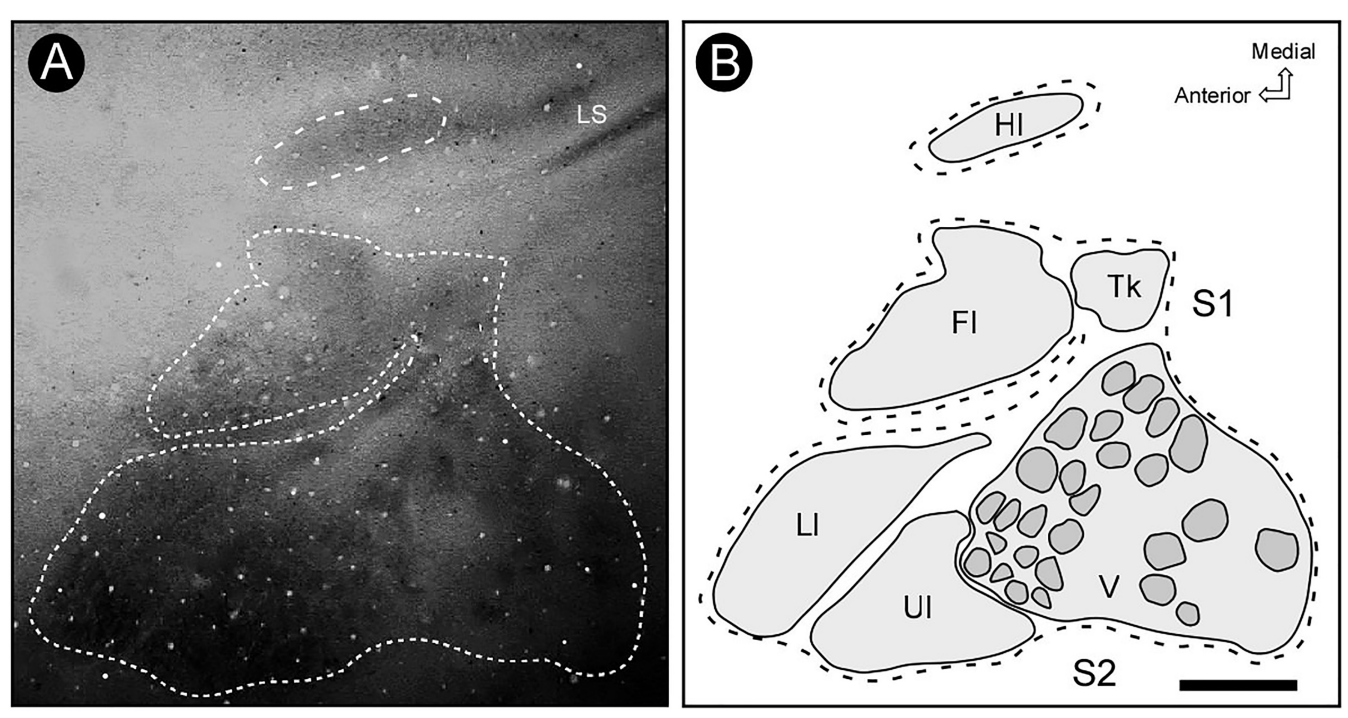

FIGURE 6 | Pattern of cytochrome oxidase (CO) reactivity across S1 area. (A) The CO pattern of distribution delimits precisely the distinct representations of the contralateral surface, which are congruent with the electrophysiologically defined borders - lips, limbs, trunk and also modules corresponding to individual vibrissae, in homology to the barrel field of small rodents (mouse and rat). (B) Reconstruction of histochemical limits of distinct regions in S1, including cortical modules in the representation of the face. Scale bar: $2 \mathrm{~mm}$. Fl, forelimb; HI, hindlimb; LI, lower lip; Tk, trunk; Ul, upper lip; V, vibrissae; LS, lateral sulcus.
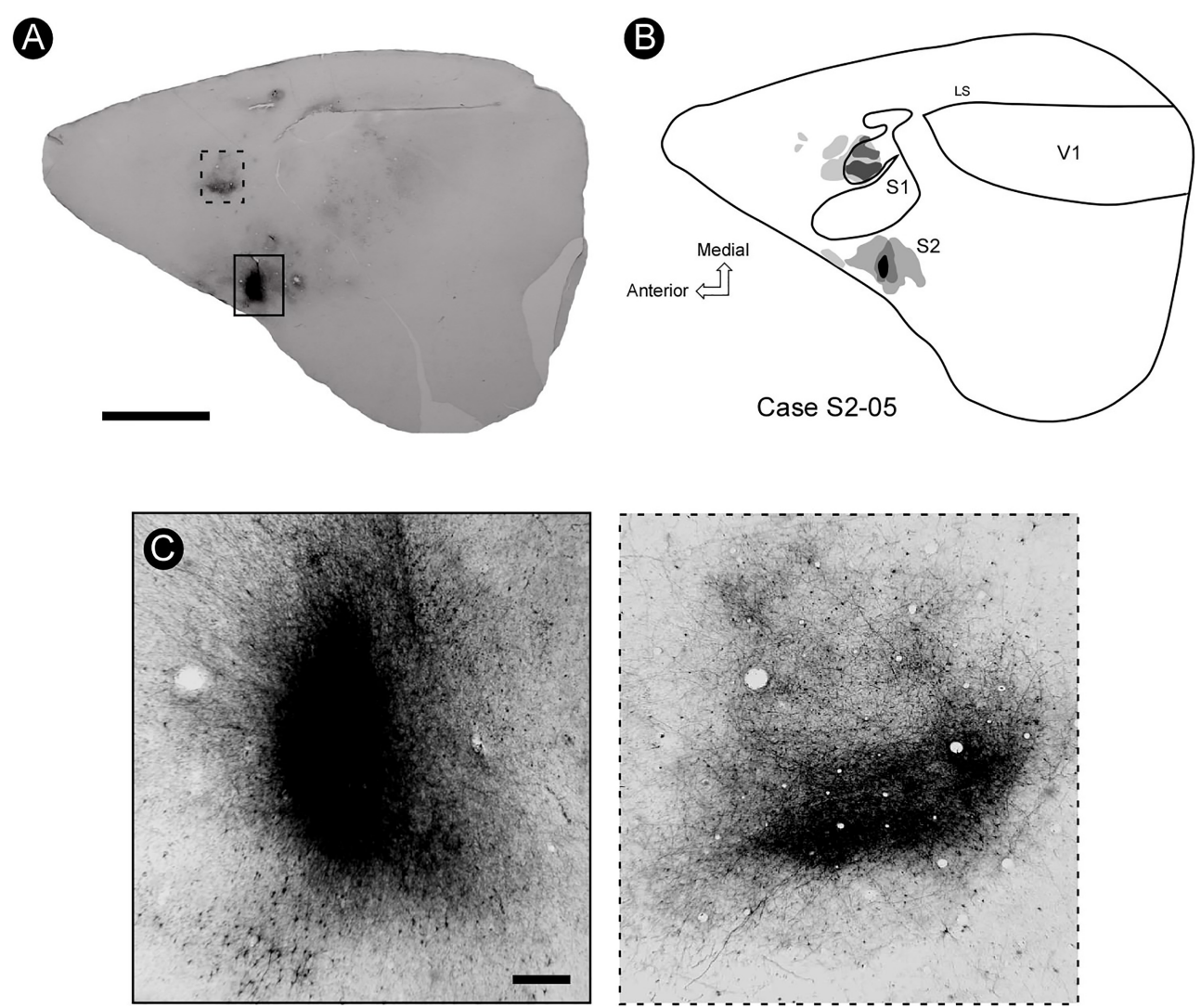

FIGURE 7 | The pattern of connectivity between S2 and S1. (A) BDA injection (marked with a solid rectangle) in the representation of the forelimb in S2 is connected with its counterpart region in $\mathrm{S} 1$, as revealed by a dense focus of projection (dashed rectangle). (B) General reconstruction of a tangential section showing the site of injection of BDA in S2 and its projection to S1. It is possible to identify two foci located rostrally to this region, as well as a small focus near the rhinal fissure, probably area PR. (C) Enlargement of the site of injection in S2 (left) and the focus of projection in S1 (right). Scale bars: A: 5 mm; B,C: $500 \mu \mathrm{m}$. LS, lateral sulcus. 

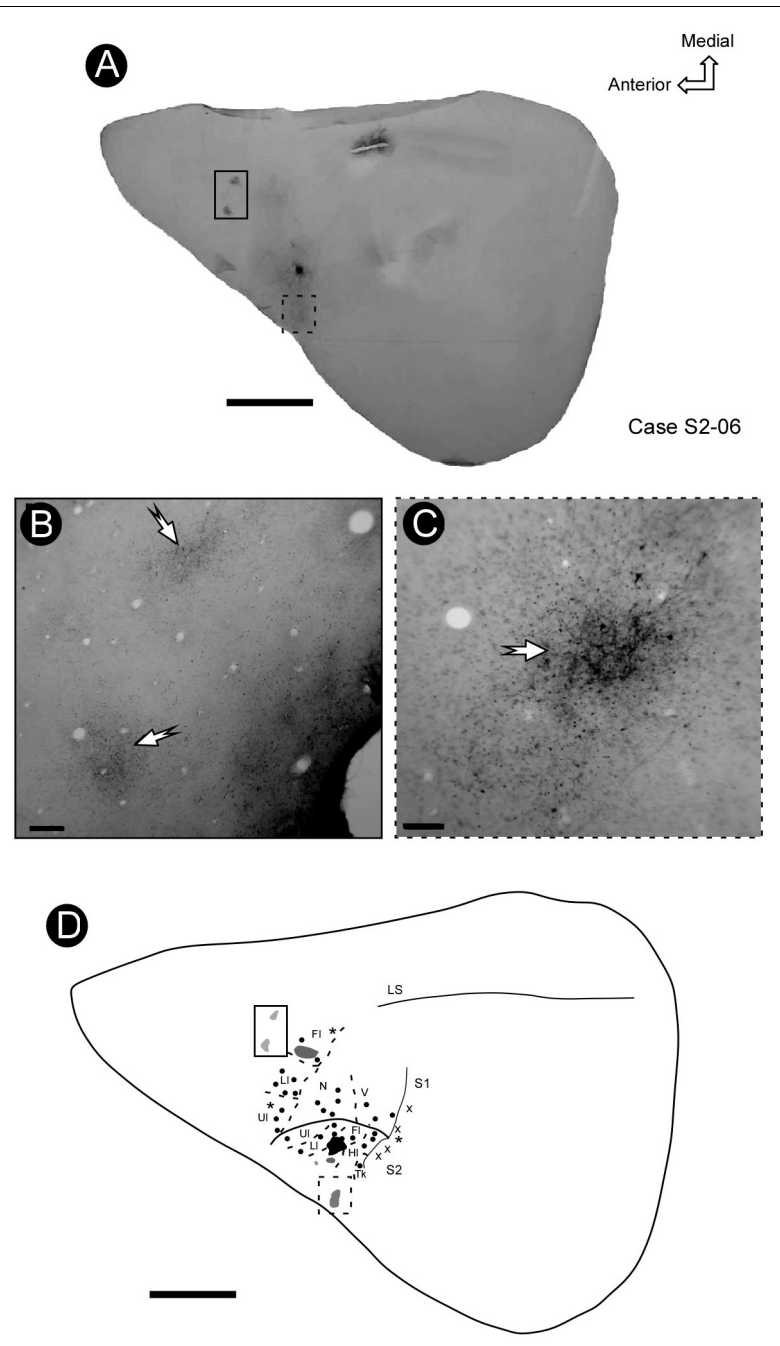

FIGURE 8 | The pattern of connectivity between S2 and S1. (A) BDA injection in the representation of the forelimb in S2 (arrow). (B,C) Micrograph amplification showing the foci of projection from the region of forelimb representation in S2 to the rostral part of S1 (solid rectangle) and lateral part of S2 (dashed rectangle), respectively (arrows). (D) Electrophysiological mapping of S1 and S2, focusing on the representation of the forelimb, showing the site of injection in S2 (black spot), its projection to S1 (gray spot) and some additional foci located in a rostral region of $\mathrm{S} 1$ and area PR. Scale bars: $\mathbf{A , D}$ : $5 \mathrm{~mm}$; B,C: $500 \mu \mathrm{m}$. LS, lateral sulcus.

\section{Cytochrome Oxidase Reactivity}

In the brain sections reacted for $\mathrm{CO}$ (see Figure 2), the histochemical pattern found in S2 differed from that in S1. While the former appeared as a region of moderate staining intensity, the later was more intensely reacted. With the help of $\mathrm{CO}$ histochemistry it was possible to discern the border between the two areas, which was characterized by a narrow strip of a strongly reactive cortex (Figure 2). It was possible in S1 to identify labeling patterns associated with distinct representations of the body, such as lips, limbs, trunk and also modules corresponding to individual vibrissae, in homology to the barrel field of small rodents (mouse and rat) (Figure 6); such subdivisions were not identified in S2 (Figure 2). Putative auditory and visual areas, identified by comparison with previously published work (Picanço-Diniz et al., 1989; Elston et al., 2006) were also intensely stained by the $\mathrm{CO}$ histochemistry. Visual areas occupied the end-third of the isocortex and the auditory area appeared as a highly reactive oval-shaped region located in more lateral and posterior regions of the cortex, immediately caudal to S2 (Figure 2).

\section{Ipsilateral Connection Patterns Revealed by BDA}

Injection of BDA in the forelimb representation of S2 resulted in a consistent pattern of intrinsic labeling defined by a central, strongly stained circular region surrounded by a less dense cloud where cell bodies, dendrites, and well-defined axon fragments could be discerned (Figure 7). The average diameter of the core injection region varied between 0.5 and $2.5 \mathrm{~mm}$. A prominent homotopic ipsilateral connection from the forelimb representation in S2 to its counterpart in S1 was also found (Figures 7A,C), supporting the notion that similar body representation fields in S2 and S1 are strongly interconnected. Some heterotopic projections from the forelimb representation in S2 to the vibrissae representation in S1 were also identified (Figure 7B).

In some cases, it was possible to identify a sparse focus of labeled projection to a region immediately rostral to S1, presumably corresponding to the motor cortex (Figures $\mathbf{8 A}, \mathbf{B}$ ). In addition, a less dense focus was also found in the more lateral and caudal regions of deeper tangential sections of the parietal cortex, close to the rhinal sulcus (Figure 8C), probably corresponding to area PR.

\section{DISCUSSION}

In the present work we describe the somatotopic organization and areal limits of the second somatosensory area (S2) located in the parietal cortex of a South American rodent, the agouti. We also compared the somatotopic map of the agouti's S2 with both the pattern of intrahemispheric corticocortical connections originating in S2 and the chemoarchitectonic pattern revealed by $\mathrm{CO}$ histochemistry. Below, we discuss these findings in more detail.

\section{The Topographic Organization of Agouti's S2: A Shared Rodent Plan}

In addition to $\mathrm{S} 1$, there is at least one more lateral somatosensory area in mammals, corresponding to S2 (Kaas, 2000; Krubitzer and Kahn, 2003). This shared primitive trait is a synapomorphy retained from a common mammalian ancestor (see Northcutt and Kaas, 1995). Our present results show that, as in other mammals, the agouti's S2 has a topographically organized representation of the contralateral body's surface, with the representation of the face located more medially in the parietal cortex and the representations of both the forelimb and the hindlimb found more laterally, bordering the rhinal sulcus (Welker and Sinha, 1972; Campos and Welker, 1976; 
Nelson et al., 1979; Carvell and Simons, 1986; Krubitzer et al., 1986; Koralek et al., 1990; Slutsky et al., 2000; Remple et al., 2003; Sarko et al., 2011). A previous study by Pimentel-Souza et al. (1980) reported the presence of a bilateral representation of the body surface in the agouti's S2. However, those authors used surface macro electrodes to map S2's topography based on lowresolution slow-wave recordings, which may have contributed to the discordant results.

One important finding is that the basic organizational layout of cortical somatosensory fields in rodents, concerning both the number and organization of related areas, is retained in the lineage, independent of the volume of the brain (Divac, 1995; Clark et al., 2001). Thus, at least in the somatosensory cortex, the size of individual brain areas scales with overall brain volume. In all rodents studied so far S1 is densely and topographically connected with S2, even in rodents with markedly distinct lifestyles and habits such as the mouse, the squirrel and the fossorial naked-mole rat (Krubitzer et al., 1986; Carvell and Simons, 1987; Henry and Catania, 2006). Reciprocal corticocortical connections between homotypical regions of S1 and S2 areas have been systematically established in several mammalian lineages (Catania and Kaas, 2001; Disbrow et al., 2003; Liao and Yen, 2008). By the same token, we identified a similar correspondence in connectivity between S1 and S2 in the agouti, suggesting that this pattern remains across mammalian species with distinct habits, lifestyles and brain structure.

\section{Supplementary Somatosensory Areas in the Parietal Cortex}

The matter of the presence and location of supplementary somatosensory areas in the parietal cortex of rodents remains undefined. Although PV has already been identified in the laboratory rat (Fabri and Burton, 1991; Remple et al., 2003), squirrels, marsupials and primates (see Karlen and Krubitzer, 2007; Kaas et al., 2018 for reviews) it has not been reported in the mouse (Carvell and Simons, 1986) and in some species of insectivores (Catania, 2000) and small marsupials (Huffman et al., 1999; Catania et al., 2000b). Even though we could not find an additional representation of the contralateral body periphery situated in the more lateral portion of the parietal cortex, we cannot rule out the existence of additional unimodal secondary somatosensory areas in the agouti, given that PV, for instance, may be located far more laterally in the parietal operculum and thus more inaccessible to electrophysiological recordings with conventional microelectrodes. Conversely, as seen in other rodents (Krubitzer et al., 1986; Brett-Green et al., 2004), it can be speculated that there are no additional secondary somatosensory areas besides S 2 in this species. Though the agouti has a brain considerably larger than the rat's, the smaller number of somatosensory cortical areas in the former may be associated with adaptations to a diurnal lifestyle (Divac, 1995), as seen in diurnal caviomorphs such as guinea pig and degu (Grant et al., 2017; Refinetti and Kenagy, 2018), and also in nocturnal noncaviomorphs (Campi and Krubitzer, 2010). Similar to another diurnal rodent, the squirrel, the agouti has a larger proportion of its dorsolateral cortex devoted to visual areas when compared to nocturnal rodents such as the rat (Picanço-Diniz et al., 1989; Campi and Krubitzer, 2010). On the other extreme, fossorial species such as the blind-mole-rat and the naked-mole-rat present a dramatic expansion of somatosensory areas that extend far into the occipital cortex (Necker et al., 1992; Henry et al., 2006), reinforcing the notion of changes in cortical organization in function of a species' habits and lifestyle (Campi and Krubitzer, 2010).

\section{Connections From S2 in Agouti}

Evidence from other mammalian species support the notion that S2 is very well interconnected ipsilaterally with other somatosensory cortical fields [primates (Burton and Carlson, 1986; Weller and Kaas, 1987; Krubitzer and Kaas, 1990; Disbrow et al., 2003), carnivores (Hartenstein et al., 1980; Herron and Johnson, 1987), insectivores (Catania and Kaas, 2001), rodents (Krubitzer et al., 1986; Carvell and Simons, 1987; Koralek et al., 1990), marsupials (Beck et al., 1996; Elston and Manger, 1999)]. In the present study, we found a small focus of projection to deep layers of a lateral region of the parietal cortex, next to the rhinal sulcus, not reported in a previous work with the agouti (Pimentel-Souza et al., 1980). Based in its relative location, we propose that this area corresponds to the multimodal (auditory, somatosensory) parietal rhinal area (PR), first reported by Krubitzer et al. (1986) in squirrels and subsequently described in other species (Krubitzer and Kaas, 1990; Fabri and Burton, 1991).

S2 is also interconnected with both S1 and S2 of the contralateral hemisphere (Krubitzer and Kaas, 1990; Guillemot et al., 1992; Hayama and Ogawa, 1997; Catania and Kaas, 2001). The distribution of callosal connections in the mammalian

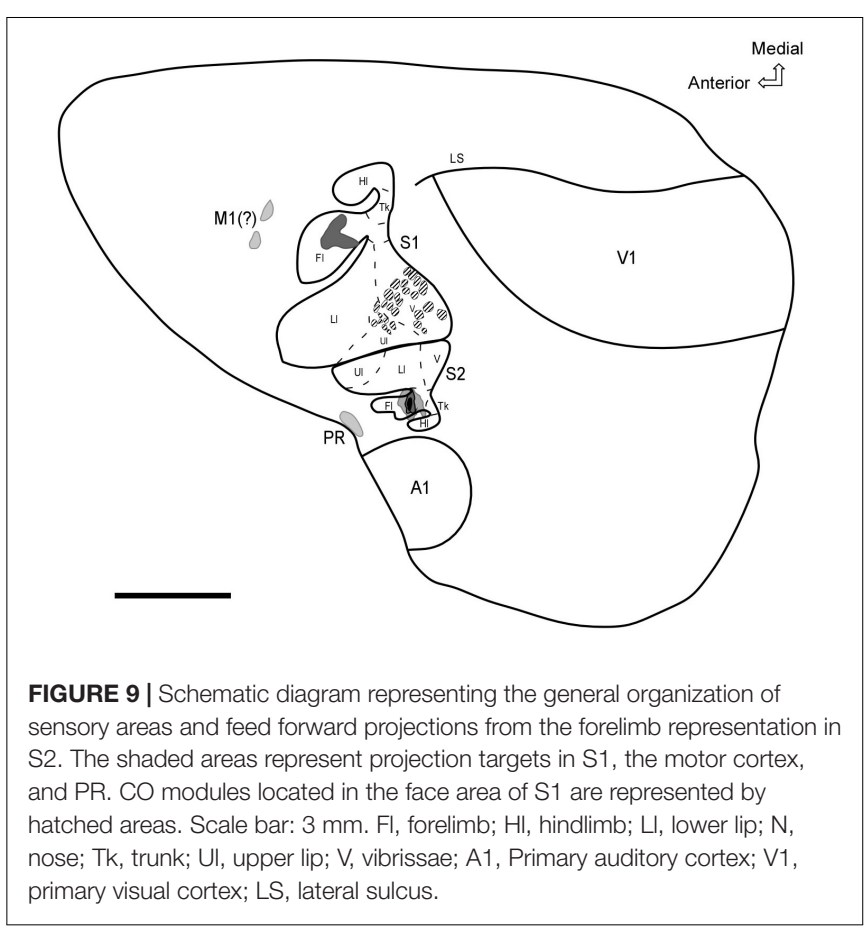


somatosensory cortex is frequently interpreted in the perspective of the "midline fusion hypothesis," which holds that one critical function of callosal connections is to generate a contiguous sensory map by connecting the representations of midline body parts in each hemisphere (Guillemot et al., 1992). Our previous results in the agouti's somatosensory cortex are in agreement with the midline hypothesis since more lateral regions of the body representation in S1 and S2 were homotopically connected with their counterparts in the contralateral hemisphere (Rocha et al., 2007); in that study we showed that callosal projections were restricted to sites in S1 and S2 in the contralateral hemisphere. Though not the focus of the present work, the absence of labeled terminals in other contralateral areas can be explained in part by the relatively small amount of neurotracer we used, in a pattern that replicates the findings of other studies (Catania and Kaas, 1997, 2001).

\section{Histochemical Limits of the Agouti's Sensory Areas}

The pattern of CO reactivity in tangential sections revealed that the organization of the agouti's auditory, somatosensory, and visual areas is similar to those described previously in the agouti and in small rodents by both histological and histochemical techniques (Wallace, 1987; Elston et al., 2006; Rocha et al., 2007, 2012; Freire et al., 2010, 2012). In addition, CO revealed the presence of conspicuous modules in the region of the face representation of $\mathrm{S} 1$, as previously described in other rodents and marsupials (Woolsey et al., 1975; Wallace, 1987; Weller, 1993; Pereira et al., 2000; Freire et al., 2005; Sarko et al., 2011). However, similar to other rodents, we did not identify the presence of cortical modules in S2 (Remple et al., 2003; Krubitzer et al., 2011; Sarko et al., 2011).

\section{CONCLUSION}

In summary, our results revealed the existence of a secondary somatosensory field (S2) with a mirror-reversed representation of S1 and located more laterally in the parietal cortex of the agouti. In addition, neurotracer injections into the forelimb representation of $\mathrm{S} 2$ revealed a dense homotopic ipsilateral projection to $\mathrm{S} 1$, supplemented by a less dense projection to $\mathrm{PR}$ located in the caudolateral cortex close to the rhinal sulcus and also to a frontal region probably associated with the motor cortex (see Figure 9).

\section{REFERENCES}

Adrian, E. D. (1940). Double representation of the feet in the sensory cortex of the cat. J. Physiol. 98, 16-18.

Alloway, K. D., Mutic, J. J., Hoffer, Z. S., and Hoover, J. E. (2000). Overlapping corticostriatal projections from the rodent vibrissal representations in primary and secondary somatosensory cortex. J. Comp. Neurol. 428, 51-67. doi: 10.1002/ 1096-9861(20001009)426:1<51::AID-CNE4>3.0.CO;2-N

Beck, P. D., Pospichal, M. W., and Kaas, J. H. (1996). Topography, architecture, and connections of somatosensory cortex in opossums: evidence for five somatosensory areas. J. Comp. Neurol. 366, 109-133. doi: 10.1002/(SICI)1096-9861(19960226)366:1<109::AID-CNE8>3.0. $\mathrm{CO} ; 2-7$
The relative location, somatotopic organization and interconnections of the agouti's S2 are similar to those described in other species, suggesting a common plan of organization for the second somatosensory area in the mammalian parietal cortex. The absence of a third somatosensory area in the agouti, such as $\mathrm{PV}$, may represent a distinct feature of this diurnal species in relation to other rodents with nocturnal habits. The allocation of cortical tissue to the processing of sensory information depends on a species lifestyle, as seen with the presence of barrels in S1 or the expansion of cortical areas devoted to visual processing in diurnal rodent species.

\section{ETHICS STATEMENT}

This study was carried out in accordance with the recommendations of the Ethics Committee for the Experimental Use of Animals of the Federal University of Pará. The protocol was approved by the Ethics Committee for the Experimental Use of Animals of the Federal University of Pará under license from the Brazilian Institute of the Environment and Renewable Natural Resources (IBAMA) - Brazil.

\section{AUTHOR CONTRIBUTIONS}

AP, JF, MF, and LS designed the study and acquired the data. AP, JF, and CP-D contributed to reagents, materials, and analysis tools. All authors analyzed and interpreted the data and wrote the manuscript.

\section{FUNDING}

This research was supported by grants from Coordenação de Aperfeiçoamento de Pessoal de Nível Superior (CAPES) and Conselho Nacional de Desenvolvimento Científico e Tecnológico (CNPq).

\section{ACKNOWLEDGMENTS}

The authors wish to thank Mr. Fabio K. L. Diamantino for the agouti's drawings.

Brett-Green, B., Paulsen, M., Staba, R. J., Fifkova, E., and Barth, D. S. (2004). Two distinct regions of secondary somatosensory cortex in the rat: topographical organization and multisensory responses. J. Neurophysiol. 91, 1327-1336. doi: $10.1152 /$ jn. 00905.2003

Burton, H., and Carlson, M. (1986). Second somatic sensory cortical area (SII) in a prosimian primate, Galago crassicaudatus. J. Comp. Neurol. 247, 200-220. doi: 10.1002/cne.902470206

Campi, K. L., and Krubitzer, L. A. (2010). Comparative studies of diurnal and nocturnal rodents: differences in lifestyle result in alterations in cortical field size and number. J. Comp. Neurol. 518, 4491-4512. doi: 10.1002/cne.22466

Campos, G. B., Johnson, J. I. Jr., and Bombardieri, R. A. Jr. (1972). Organization of tactile thalamus and related behavior in the agouti, Dasyprocta aguti. Physiol. Behav. 8, 553-556. doi: 10.1016/0031-9384(72)90346-0 
Campos, G. B., and Welker, W. I. (1976). Comparisons between brains of a large and a small hystricomorph rodent: capybara, Hydrochoerus and guinea pig, Cavia; neocortical projection regions and measurements of brain subdivisions. Brain Behav. Evol. 13, 243-266. doi: 10.1159/000123814

Carvell, G. E., and Simons, D. J. (1986). Somatotopic organization of the second somatosensory area (SII) in the cerebral cortex of the mouse. Somatosens. Res. 3, 213-237. doi: 10.3109/07367228609144585

Carvell, G. E., and Simons, D. J. (1987). Thalamic and corticocortical connections of the second somatic sensory area of the mouse. J. Comp. Neurol. 265, 409-427. doi: $10.1002 /$ cne. 902650309

Catania, K. C. (2000). Cortical organization in insectivora: the parallel evolution of the sensory periphery and the brain. Brain Behav. Evol. 55, 311-321. doi: 10.1159/000006666

Catania, K. C., Collins, C. E., and Kaas, J. H. (2000a). Organization of sensory cortex in the East African hedgehog (Atelerix albiventris). J. Comp. Neurol. 421, 256-274.

Catania, K. C., Jain, N., Franca, J. G., Volchan, E., and Kaas, J. H. (2000b). The organization of somatosensory cortex in the short-tailed opossum (Monodelphis domestica). Somatosens. Mot. Res. 17, 39-51. doi: 10.1080/ 08990220070283

Catania, K. C., and Kaas, J. H. (1997). Organization of somatosensory cortex and distribution of corticospinal neurons in the eastern mole (Scalopus aquaticus). J. Comp. Neurol. 378, 337-353. doi: 10.1002/(SICI)1096-9861(19970217)378: $3<337:: \mathrm{AID}-\mathrm{CNE} 3>3.0 . \mathrm{CO} ; 2-4$

Catania, K. C., and Kaas, J. H. (2001). Areal and callosal connections in the somatosensory cortex of the star-nosed mole. Somatosens. Mot. Res. 18, 303311. doi: 10.1080/01421590120089686

Catania, K. C., and Remple, M. S. (2002). Somatosensory cortex dominated by the representation of teeth in the naked mole-rat brain. Proc. Natl. Acad. Sci. U.S.A. 99, 5692-5697. doi: 10.1073/pnas.072097999

Clark, D. A., Mitra, P. P., and Wang, S. S. (2001). Scalable architecture in mammalian brains. Nature 411, 189-193. doi: 10.1038/3507 5564

Dias, I. A., Bahia, C. P., Franca, J. G., Houzel, J. C., Lent, R., Mayer, A. O., et al. (2014). Topography and architecture of visual and somatosensory areas of the agouti. J. Comp. Neurol. 522, 2576-2593. doi: 10.1002/cne.23550

Disbrow, E., Litinas, E., Recanzone, G. H., Padberg, J., and Krubitzer, L. (2003). Cortical connections of the second somatosensory area and the parietal ventral area in macaque monkeys. J. Comp. Neurol. 462, 382-399. doi: 10.1002/cne. 10731

Divac, I. (1995). Monotremunculi and brain evolution. Trends Neurosci. 18, 2-4. doi: 10.1016/0166-2236(95)93941-P

Dooley, J. C., Franca, J. G., Seelke, A. M., Cooke, D. F., and Krubitzer, L. A. (2015). Evolution of mammalian sensorimotor cortex: thalamic projections to parietal cortical areas in Monodelphis domestica. Front. Neuroanat. 8:163. doi: 10.3389/fnana.2014.00163

Eickhoff, S. B., Amunts, K., Mohlberg, H., and Zilles, K. (2006a). The human parietal operculum. II. Stereotaxic maps and correlation with functional imaging results. Cereb. Cortex 16, 268-279.

Eickhoff, S. B., Schleicher, A., Zilles, K., and Amunts, K. (2006b). The human parietal operculum. I. Cytoarchitectonic mapping of subdivisions. Cereb. Cortex $16,254-267$.

Elston, G. N., Elston, A., Freire, M. A. M., Gomes, Leal W, Dias, I. A., Pereira, A Jr, et al. (2006). Specialization of pyramidal cell structure in the visual areas V1, V2 and V3 of the South American rodent, Dasyprocta primnolopha. Brain Res. 1106, 99-110. doi: 10.1016/j.brainres.2006.05.100

Elston, G. N., and Manger, P. R. (1999). The organization and connections of somatosensory cortex in the brush-tailed possum (Trichosurus vulpecula): evidence for multiple, topographically organized and interconnected representations in an Australian marsupial. Somatosens. Mot. Res. 16, 312-337. doi: 10.1080/08990229970384

Fabri, M., and Burton, H. (1991). Ipsilateral cortical connections of primary somatic sensory cortex in rats. J. Comp. Neurol. 311, 405-424. doi: 10.1002/cne. 903110310

Freire, M. A. M., Faber, J., Picanço-Diniz, C. W., Franca, J. G., and Pereira, A. (2012). Morphometric variability of nicotinamide adenine dinucleotide phosphate diaphorase neurons in the primary sensory areas of the rat. Neuroscience 205, 140-153. doi: 10.1016/j.neuroscience.2011.12.029
Freire, M. A. M., Franca, J. G., Picanço-Diniz, C. W., and Pereira, A. Jr. (2005). Neuropil reactivity, distribution and morphology of NADPH diaphorase type I neurons in the barrel cortex of the adult mouse. J. Chem. Neuroanat. 30, 71-81. doi: 10.1016/j.jchemneu.2005.04.006

Freire, M. A. M., Rocha, E. G., Oliveira, J. L. F., Guimaraes, J. S., Silveira, L. C. L., Elston, G. N., et al. (2010). Morphological variability of NADPH diaphorase neurons across areas V1, V2, and V3 of the common agouti. Brain Res. 1318C, 52-63. doi: 10.1016/j.brainres.2009.12.045

Freire, M. A. M., Tourinho, S. C., Guimaraes, J. S., Oliveira, J. L. F., PicançoDiniz, C. W., Gomes-Leal, W., et al. (2008). Histochemical characterization, distribution and morphometric analysis of NADPH diaphorase neurons in the spinal cord of the agouti. Front. Neuroanat. 2:2. doi: 10.3389/neuro.05.002

Gerard, R. W., Marshall, W. H., and Saul, L. J. (1933). Cerebral action potentials. Proc. Soc. Exp. Biol. Med. 30, 1123-1125. doi: 10.3181/00379727-30-6817

Grant, R. A., Delaunay, M. G., and Haidarliu, S. (2017). Mystacial whisker layout and musculature in the guinea pig (Cavia porcellus): a social, diurnal mammal. Anat. Rec. 300, 527-536. doi: 10.1002/ar.23504

Guillemot, J. P., Richer, L., Ptito, M., Guilbert, M., and Lepore, F. (1992). Somatosensory receptive field properties of corpus callosum fibres in the raccoon. J. Comp. Neurol. 321, 124-132. doi: 10.1002/cne.903210111

Hartenstein, V., Innocenti, G. M., and Caminiti, R. (1980). An anatomical basis for the representation of the ipsilateral periphery in the second somatosensory area (S2) of the cat. Neurosci. Lett. S 5:484.

Hayama, T., and Ogawa, H. (1997). Regional differences of callosal connections in the granular zones of the primary somatosensory cortex in rats. Brain Res. Bull. 43, 341-347. doi: 10.1016/S0361-9230(97)00018-X

Henry, E. C., and Catania, K. C. (2006). Cortical, callosal, and thalamic connections from primary somatosensory cortex in the naked mole-rat (Heterocephalus glaber), with special emphasis on the connectivity of the incisor representation. Anat. Rec. A Discov. Mol. Cell. Evol. Biol. 288, 626-645. doi: 10.1002/ar.a.20328

Henry, E. C., Remple, M. S., O’Riain, M. J., and Catania, K. C. (2006). Organization of somatosensory cortical areas in the naked mole-rat (Heterocephalus glaber). J. Comp. Neurol. 495, 434-452. doi: 10.1002/cne.20883

Henry, O. (1999). Frugivory and the importance of seeds in the diet of the orangerumped agouti (Dasyprocta leporina) in French Guiana. J. Trop. Ecol. 15, 291-300. doi: 10.1017/S0266467499000826

Herron, P., and Johnson, J. I. (1987). Organization of intracortical and commissural connections in somatosensory cortical areas I and II in the raccoon. J. Comp. Neurol. 257, 359-371. doi: 10.1002/cne.902570305

Huffman, K. J., Nelson, J., Clarey, J., and Krubitzer, L. (1999). Organization of somatosensory cortex in three species of marsupials, Dasyurus hallucatus, Dactylopsila trivirgata, and Monodelphis domestica: neural correlates of morphological specializations. J. Comp. Neurol. 403, 5-32. doi: 10.1002/(SICI) 1096-9861(19990105)403:1<5::AID-CNE2>3.0.CO;2-F

Huntenburg, J. M., Bazin, P. L., and Margulies, D. S. (2017). Large-scale gradients in human cortical organization. Trends Cogn. Sci. 22, 21-31. doi: 10.1016/j.tics. 2017.11.002

Jacobs, B., Harland, T., Kennedy, D., Schall, M., Wicinski, B., Butti, C., et al. (2015). The neocortex of cetartiodactyls. II. Neuronal morphology of the visual and motor cortices in the giraffe (Giraffa camelopardalis). Brain Struct. Funct. 220, 2851-2872. doi: 10.1007/s00429-014-0830-9

Kaas, J. H. (1989). Why does the brain have so many visual areas? J. Cogn. Neurosci. 1, 121-135. doi: 10.1162/jocn.1989.1.2.121

Kaas, J. H. (2000). Organizing principles of sensory representations. Novartis Found. Symp. 228, 188-198; discussion 198-205. doi: 10.1002/0470846631.ch13

Kaas, J. H. (2011). Reconstructing the areal organization of the neocortex of the first mammals. Brain Behav. Evol. 78, 7-21. doi: 10.1159/000327316

Kaas, J. H., Qi, H. X., and Stepniewska, I. (2018). The evolution of parietal cortex in primates. Handb. Clin. Neurol. 151, 31-52. doi: 10.1016/B978-0-444-636225.00002-4

Karlen, S. J., and Krubitzer, L. (2007). The functional and anatomical organization of marsupial neocortex: evidence for parallel evolution across mammals. Prog. Neurobiol. 82, 122-141. doi: 10.1016/j.pneurobio.2007.03.003

Koralek, K. A., Olavarria, J., and Killackey, H. P. (1990). Areal and laminar organization of corticocortical projections in the rat somatosensory cortex. J. Comp. Neurol. 299, 133-150. doi: 10.1002/cne.902990202

Krubitzer, L. A. (1995). The organization of neocortex in mammals: are species differences really so different? Trends Neurosci. 18, 408-417. 
Krubitzer, L. A. (1998). What can monotremes tell us about brain evolution? Philos. Trans. R. Soc. Lond. B Biol. Sci. 353, 1127-1146. doi: 10.1098/rstb.1998.0271

Krubitzer, L. A., Campi, K. L., and Cooke, D. F. (2011). All rodents are not the same: a modern synthesis of cortical organization. Brain Behav. Evol. 78, 51-93. doi: $10.1159 / 000327320$

Krubitzer, L. A., and Kaas, J. H. (1990). The organization and connections of somatosensory cortex in marmosets. J. Neurosci. 10, 952-974. doi: 10.1523/ JNEUROSCI.10-03-00952.1990

Krubitzer, L. A., and Kahn, D. M. (2003). Nature versus nurture revisited: an old idea with a new twist. Prog. Neurobiol. 70, 33-52. doi: 10.1016/S0301-0082(03) 00088-1

Krubitzer, L. A., Sesma, M. A., and Kaas, J. H. (1986). Microelectrode maps, myeloarchitecture, and cortical connections of three somatotopically organized representations of the body surface in the parietal cortex of squirrels. J. Comp. Neurol. 250, 403-430. doi: 10.1002/cne.902500402

Liao, C. C., and Yen, C. T. (2008). Functional connectivity of the secondary somatosensory cortex of the rat. Anat. Rec. 291, 960-973. doi: 10.1002/ar.20696

Manger, P. R., Cort, J., Ebrahim, N., Goodman, A., Henning, J., Karolia, M., et al. (2008). Is 21 st century neuroscience too focussed on the rat/mouse model of brain function and dysfunction? Front. Neuroanat. 2:5. doi: 10.3389/neuro.05. 005.2008

Marshall, W. H., Woolsey, C. N., and Bard, P. (1937). Cortical representation of tactile sensibility as indicated by cortical potentials. Science $85,388-390$. doi: $10.1126 /$ science. 85.2207 .388

Metzner, W., and Juranek, J. (1997). A sensory brain map for each behavior? Proc. Natl. Acad. Sci. U.S.A. 94, 14798-14803. doi: 10.1073/pnas.94.26.14798

Moss, C. F. (2018). "A comparative approach is imperative for the understanding of brain function," in Think Tank: Forty Neuroscientists Explore the Biological Roots of Human Experience, ed. D. J. Linden (New Haven, CT: Yale University Press).

Necker, R., Rehkamper, G., and Nevo, E. (1992). Electrophysiological mapping of body representation in the cortex of the blind mole rat. Neuroreport 3, 505-508. doi: 10.1097/00001756-199206000-00012

Nelson, R. J., Sur, M., and Kaas, J. H. (1979). The organization of the second somatosensory area (SmII) of the grey squirrel. J. Comp. Neurol. 184, 473-489. doi: 10.1002/cne.901840304

Northcutt, R. G., and Kaas, J. H. (1995). The emergence and evolution of mammalian neocortex. Trends Neurosci. 18, 373-379. doi: 10.1016/01662236(95) $93932-\mathrm{N}$

Nowak, R. M., and Walker, E. P. (1999). Walker's Mammals of the World, Vol. 1. Baltimore, MD: JHU Press.

Patel, G. H., Kaplan, D. M., and Snyder, L. H. (2014). Topographic organization in the brain: searching for general principles. Trends Cogn. Sci. 18, 351-363. doi: 10.1016/j.tics.2014.03.008

Patzke, N., Bertelsen, M. F., Fuxe, K., and Manger, P. R. (2014). Nuclear organization of cholinergic, catecholaminergic, serotonergic and orexinergic systems in the brain of the Tasmanian devil (Sarcophilus harrisii). J. Chem. Neuroanat. 6, 94-106. doi: 10.1016/j.jchemneu.2014.08.005

Pereira, A. Jr., Freire, M. A. M., Bahia, C. P., Franca, J. G., and Picanço-Diniz, C. W. (2000). The barrel field of the adult mouse SmI cortex as revealed by NADPHdiaphorase histochemistry. Neuroreport 11, 1889-1892. doi: 10.1097/00001756200006260-00017

Picanço-Diniz, C. W., Oliveira, H. L., Silveira, L. C. L., and Oswaldo-Cruz, E. (1989). The visual cortex of the agouti (Dasyprocta aguti): architectonic subdivisions. Braz. J. Med. Biol. Res. 22, 121-138.

Pimentel-Souza, F., Cosenza, R. M., Campos, G. B., and Johnson, J. I. (1980). Somatic sensory cortical regions of the agouti, Dasyprocta aguti. Brain Behav. Evol. 17, 218-240. doi: 10.1159/000121801

Refinetti, R., and Kenagy, G. J. (2018). Diurnally active rodents for laboratory research. Lab. Anim. 52, 577-587. doi: 10.1177/0023677218771720

Remple, M. S., Henry, E. C., and Catania, K. C. (2003). Organization of somatosensory cortex in the laboratory rat (Rattus norvegicus): evidence for two lateral areas joined at the representation of the teeth. J. Comp. Neurol. 467, 105-118. doi: 10.1002/cne.10909
Rocha, E. G., Freire, M. A. M., Pereira, A., Sosthenes, M. C., Silveira, L. C., Elston, G. N., et al. (2012). Dendritic structure varies as a function of eccentricity in V1: a quantitative study of NADPH diaphorase neurons in the diurnal South American rodent agouti, Dasyprocta prymnolopha. Neuroscience 216, 94-102. doi: 10.1016/j.neuroscience.2012.04.042

Rocha, E. G., Santiago, L. F., Freire, M. A. M., Gomes-Leal, W., Lent, R., Houzel, J. C., et al. (2007). Callosal axon arbors in the limb representations of the somatosensory cortex (SI) in the agouti (Dasyprocta primnolopha). J. Comp. Neurol. 500, 255-266. doi: 10.1002/cne.21167

Santiago, L. F., Rocha, E. G., Freire, M. A. M., Lent, R., Houzel, J. C., Picanço-Diniz, C. W., et al. (2007). The organizational variability of the rodent somatosensory cortex. Rev. Neurosci. 18, 283-294. doi: 10.1515/REVNEURO.2007.18. $3-4.283$

Santiago, L. F., Rocha, E. G., Santos, C. L., Pereira, A Jr, Franca, J. G., and Picanço-Diniz, C. W. (2010). S1 to S2 hind- and forelimb projections in the agouti somatosensory cortex: axon fragments morphological analysis. J. Chem. Neuroanat. 40, 339-345. doi: 10.1016/j.jchemneu.2010.09.005

Sarko, D. K., Leitch, D. B., Girard, I., Sikes, R. S., and Catania, K. C. (2011). Organization of somatosensory cortex in the Northern grasshopper mouse (Onychomys leucogaster), a predatory rodent. J. Comp. Neurol. 519, 64-74. doi: $10.1002 /$ cne.22504

Shu, S. Y., Ju, G., and Fan, L. Z. (1988). The glucose oxidase-DAB-nickel method in peroxidase histochemistry of the nervous system. Neurosci. Lett. 85, 169-171. doi: 10.1016/0304-3940(88)90346-1

Slutsky, D. A., Manger, P. R., and Krubitzer, L. (2000). Multiple somatosensory areas in the anterior parietal cortex of the California ground squirrel (Spermophilus beecheyii). J. Comp. Neurol. 416, 521-539. doi: 10.1002/(SICI) 1096-9861(20000124)416:4<521::AID-CNE8>3.0.CO;2-\#

Wallace, M. N. (1987). Histochemical demonstration of sensory maps in the rat and mouse cerebral cortex. Brain Res. 418, 178-182. doi: 10.1016/0006-8993(87) 90977-2

Wandell, B. A., Dumoulin, S. O., and Brewer, A. A. (2007). Visual field maps in human cortex. Neuron 56, 366-383. doi: 10.1016/j.neuron.2007.10.012

Welker, C., and Sinha, M. M. (1972). Somatotopic organization of Smll cerebral neocortex in albino rat. Brain Res. 37, 132-136. doi: 10.1016/0006-8993(72) 90354-X

Weller, R. E., and Kaas, J. H. (1987). Subdivisions and connections of inferior temporal cortex in owl monkeys. J. Comp. Neurol. 256, 137-172. doi: 10.1002/ cne. 902560112

Weller, W. L. (1993). SmI cortical barrels in an Australian marsupial, Trichosurus vulpecula (brush-tailed possum): structural organization, patterned distribution, and somatotopic relationships. J. Comp. Neurol. 337, 471-492. doi: $10.1002 /$ cne. 903370310

Wilson, D. E., and Reeder, D. M. (2005). Mammals Species of the World. A Taxonomic and Geographic Reference, Third Edn. Baltimore, MD: The Johns Hopkins University Press.

Wong-Riley, M. (1979). Columnar cortico-cortical interconnections within the visual system of the squirrel and macaque monkeys. Brain Res. 162, 201-217. doi: 10.1016/0006-8993(79)90284-1

Woolsey, T. A., Welker, C., and Schwartz, R. H. (1975). Comparative anatomical studies of the SmI face cortex with special reference to the occurrence of "barrels" in layer IV. J. Comp. Neurol. 164, 79-94. doi: 10.1002/cne.901640107

Conflict of Interest Statement: The authors declare that the research was conducted in the absence of any commercial or financial relationships that could be construed as a potential conflict of interest.

Copyright (c) 2019 Santiago, Freire, Picanço-Diniz, Franca and Pereira. This is an open-access article distributed under the terms of the Creative Commons Attribution License (CC BY). The use, distribution or reproduction in other forums is permitted, provided the original author(s) and the copyright owner(s) are credited and that the original publication in this journal is cited, in accordance with accepted academic practice. No use, distribution or reproduction is permitted which does not comply with these terms. 